\section{REFITRENCES}

Baker, O., 1954, Simultaneous fiow of oil and gas. Oil Gas $J$ $53,185-191$.

Charpentier, J. C. and Favier, M., 1975, Some liquid hold-up experimental data in trickle-bed reactors for foaming and non-foaming hydrocarbons. A.I.Ch.E. J. 21, 1213-1218.

Talmor, E., 1977, Two phase downflow through catalyst beds. A.I.Ch.E. J. 23, 868-874.
Tosun, G., 1984, A study of cocurrent downflow of nonfoaming gas-liquid systems in a packed-bed. Ind. Engng Chem. Process Des. Dev. 23, 29-35.

Wammes, W. J. A., Mechielsen, S. J. and Westerterp, K. R., 1990 , The transition between trickle flow and pulse flow in a cocurrent gas-liquid trickle-bed reactor at elevated pressures. Chem. Engng Sci. 45, 3149-3158.

\title{
Authors' reply to comments by G. Tosun
}

(Received 8 March 1991; accepted 23 April 1991)

Dear Sirs,

Unfortunately our statement "In the diagram of Charpentier and Favier (1975) the transition line at elevated pressures shifts towards higher values of $G / \lambda$ "may be misinterpreted. We fully agree with the comment of Tosun that the correlation of Charpentier and Favier is a geteralized correlation and does not move at all. What we intended to state is illustrated in Fig. 1. For a given gas density, our transition points can be described by a straight line, approximately parallel to the line of Charpentier and Favier. At a given higher gas density, the line which correlates the transition points shifts towards the right-hand side in this diagram. Hence, at higher gas densities the transition cannot be described by the correlation of Charpentier and Favier. We regret that the discussion of these results is not completely clear in our paper. The nice analysis, as given in Tosun's comments, of the density influence on the operating conditions at the flow-regime transition as predicted by the Charpentier and Favier diagram, shows indeed more clearly that this diagram is not able to predict our experimental findings.

The omission of the work Tosun (1984) is unfortunate indeed because his major conclusions are concerned with the applicability of the flow diagrams of Charpentier and Favier (1975) and Talmor (1977) which was also part of our work Tosun also varied the gas density and performed his experiments in the range $0.08<\rho,<1.8 \mathrm{~kg} / \mathrm{m}^{3}$. In his comments Tosun mentions that he had not found any influence of the gas density. In the papet Tosun (1984) he shows that for $G / \lambda>0.05$ his data agree reasonably well with the diagram of Charpentier and Favier. However, the fact that his line has a slope of -1.0 , which means no influenve of the gas density, is difficult to read from his Fig. 7 and was not explicitly mentioned. Neither could we draw some conelusions about influence of the gas density from his Fig. 3 as the exact values of the gas and liquid velocities at transition are difficult to derive from his logarithmically scaled figure. To this point we may add that we also performed experiments in

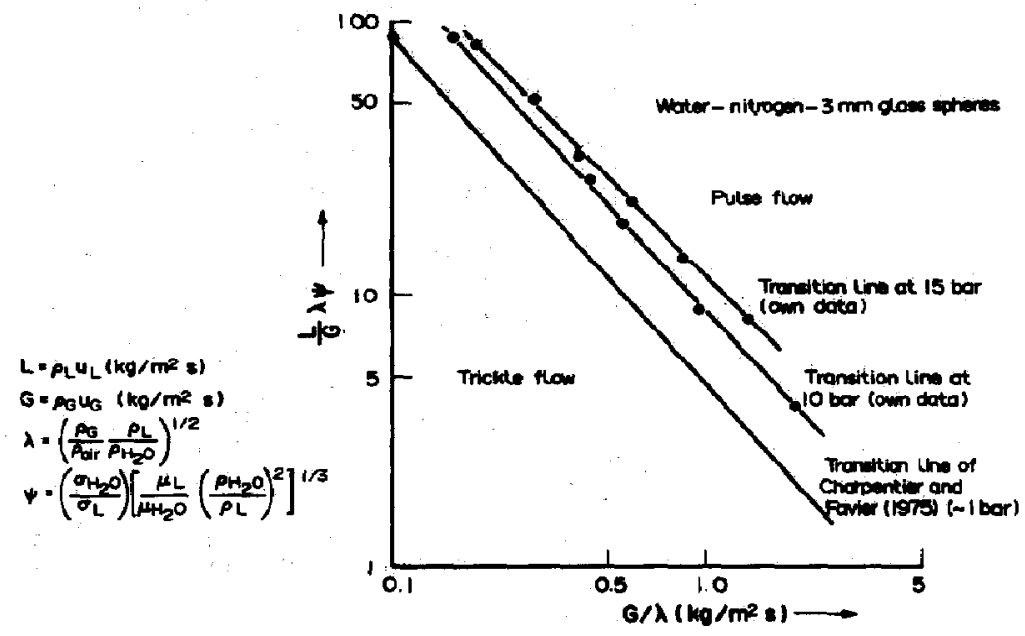

Fig. 1. Some of our results at elevated pressures in a Charpentier and Favier plot. 


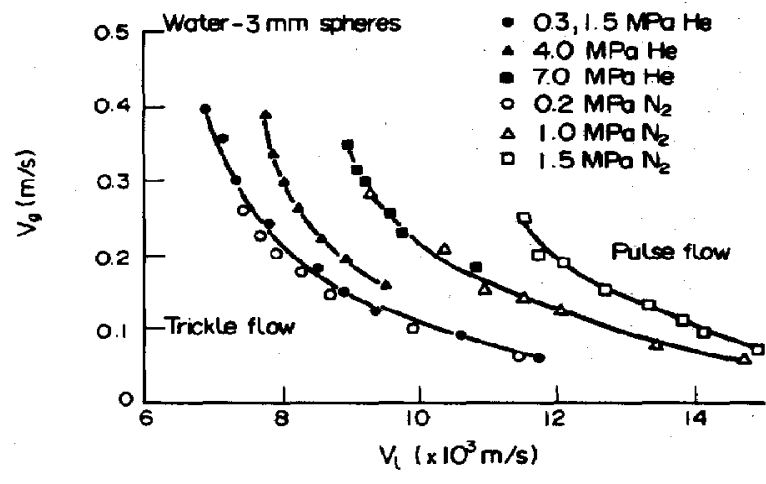

Fig. 2. Influence of the gas density on the boundary between trickle and pulse flow.

the range $0.5<\rho_{g}<2.5 \mathrm{~kg} / \mathrm{m}^{3}$, see Fig. 2 . The $G / \lambda$ values are all larger than 0.05 . The transition data determined in this density range are reasonably described by the transition correlation of Charpentier and Favier. However, the slope of our line in the Charpentier-diagram is -1.0 as we also found no influence in this gas-density range. So at relatively low gas densities we arrive at the same conclusion as Tosun.

W. J. A. WAMMES S. J. MECHIELSEN K. R. WESTERTERP'

Department of Chemical Engineering

Twente University of Technology

PO Box 217, 7500 AE Enschede

The Netherlands

\section{REFERENCES}

Charpentier, J. C. and Favier, M., 1975, Some liquid hold-up experimental data in trickle bed reactors for foaming and non-foaming hydrocarbons. A.I.Ch.E. J. 21, 1213-1218.

Talmor, E., 1977, Two phase downflow through catalyst beds. A.I.Ch.E. J. 23, 868-874.

Tosun, 1984, A study of cocurrent downflow of non-foaming gas-liquid systems in a packed bed. Ind. Engng Chem. Process Des. Dev. 23. 29-35.

†Athor to whom correspondence should be addreseed.

\section{Comments on mitigation of backmixing via catalyst dilution}

(Recelved 13 June 1991; accepted 5 July 1991)

\section{Dear Sirs,}

Ho and White (1991) have recently proved the very interesting result (hitherto apparently known only in practice) that catalyst dilution can to some extent make up for the loss of conversion induced by backmixing or longitudinal dispersion in a tubular reactor. They used the sequence of $N$ stirred tanks as a model of the tubular reactor with dispersion and proved the result for $m$ th-order reaction, with a special proof for the case $m=1$. This letter is just to point out that the result also holds for any monotonic kinetics $r(c), r(0)=0$, $r^{\prime}(c)>0$, and to show how the difierential equation model of the packed bed can be used to obtain the same result.

The latter is $D\left(\mathrm{~d}^{2} c / d z^{2}\right)-v(\mathrm{~d} c / \mathrm{d} z)-\mathrm{r}(c)=0$ in $0<z<L,-D(\mathrm{~d} c / \mathrm{d} z)+c=c_{0}$ at $z=0$, (dc/dz)=0 at $z=L$. In this equation set $x=r\left(c_{0}\right) z / v c_{0}, X=r\left(c_{0}\right) L / v c_{0}$, $u=c / c_{0}, \rho(u)=r\left(c_{0} u\right) / r\left(c_{0}\right)$ and $\Delta=\operatorname{Dr}\left(c_{0}\right) / v^{2} c_{0}$, then the equations are $\Delta u^{\prime \prime}-u^{\prime}-\rho(u)=0,-\Delta u^{\prime}(0)+u(0)=1$, $u^{\prime}(X)=0$. Now dilution does not change $X$, since $r$ becomes $r / R$ and $L$ becomes $L R, R$ being $H o$ and White's dilution factor. However $\Delta$ becomes $\Delta / R$, which means that the behavior of the reactor is precisely that of an undiluted bed with the smaller dispersion coefficient $D / R$. This gives a precise and simple description of the mitigation by dilution in the difierential equation model and adds another example of the usefulness of arguing from the properties of models [ $\mathrm{cl}$. the Danckwerts Lecture printed by chance in the same issue as Ho and White's shorter communication (Aris, 1991, pp. 1537-1538)].
The generalization of Ho and White's result to arbitrary monotonic kinetics rests on the fact that the $\boldsymbol{N}$ stirred tani model provides a homotopy between the single stirred tank $(N=1)$ and the plug fow reactor without dispersion $(N \rightarrow \infty)$. If $c_{u}$ denotes the concentration in the $n$th tank of a sequence of $N$, each of residence time $\theta / N$, then

$$
c_{n-1}=c_{n}+(\theta / N) r\left(c_{n}\right)=f\left(c_{n} ; \theta / N\right) \text {. }
$$

The feed concentration $c_{0}$ may be used to make the concentration dimensionless, $x_{n}=c_{n} / c_{0}$. Also let the Damkohler number be $D a=\theta r\left(c_{0}\right) / c_{0}$ and $\rho(x)=r\left(c_{0} x\right) / r\left(c_{0}\right)$, giving

$$
x_{n-1}-x_{n}+(D a / N) \rho\left(x_{n}\right)-F\left(x_{n} ; D a / N\right) \text {. }
$$

The exit concentration $x_{N}=F^{-N}(1 ; D a / N)$ can be calculated as the $N$ th iterate of the inverse function of $F$ and the following inequalities can be easily shown to hold:

$$
\begin{gathered}
1>x_{1}>\cdots>x_{N}>\cdots>x_{N}>0, \\
1-x_{1}>x_{1}-x_{2}>\cdots>x_{N-1}-x_{N}, \\
\operatorname{Dap}(x)>1-x_{N}>\operatorname{Dap}\left(x_{N}\right) .
\end{gathered}
$$

More subtle are the relations betwoen $F(x, D a / N)$ and $F[x, D a /(N+1)]$, of which the inequalities we need are:

$$
\begin{aligned}
& 1>F^{-1}[1 ; D a /(N+1)]>F^{-1}(1 ; D a / N)> \\
& F^{-2}[1 ; D a /(N+1)]>\cdots
\end{aligned}
$$

